\title{
China's Pollution-Intensive Industry Transfer Path and Driving Factors-An Empirical Study Based on Spatial Panel Model
}

\author{
Qingyuan Lin \\ JiNan University, Guangzhou, China \\ Email: 490946359@qq.com
}

How to cite this paper: Lin, Q.Y. (2017) China's Pollution-Intensive Industry Transfer Path and Driving Factors-An Empirical Study Based on Spatial Panel Model. iBusiness, 9, 13-30.

https://doi.org/10.4236/ib.2017.91002

Received: February 16, 2017

Accepted: March 18, 2017

Published: March 21, 2017

Copyright $\odot 2017$ by author and Scientific Research Publishing Inc. This work is licensed under the Creative Commons Attribution International License (CC BY 4.0).

http://creativecommons.org/licenses/by/4.0/

\section{(c) (i) Open Access}

\begin{abstract}
In this paper, global spatial autocorrelation analysis and spatial Durbin model regression analysis of spatial panel data from 30 regions in China from 2002 to 2014 are carried out to explore the diversion path and driving factors of China's pollution-intensive industries from the perspective of spatial correlation. The results show that the spatial distribution of regional pollution intensive industry in China has significantly spatial dependence. The pollution-intensive industries in various regions continue to carry out spatial dynamic transitions, roll-in and roll-out, and the central and western regions undertake the pollution intensive enterprises which transferred from the eastern coastal areas. In terms of driving factors of pollution intensive industries transfer, agglomeration, transportation infrastructure, technological progress and capital investment, which have played a positive role in promoting, labor costs have negative effect. Environmental regulation of pollution intensive industry transfer has a dual role, namely "crowding out" and "innovation effect". It is recommended that pollution-intensive enterprises should have scientific planning and follow the correct transfer path.
\end{abstract}

\section{Keywords}

Pollution-Intensive Industry, Industrial Transfer, Space Panel Regression

\section{Introduction}

Since the reform and opening up, along with China's rapid industrialization and urbanization, the economy has been rapidly developed, and national requirement for the quality of economic development and people in the improvement of environmental quality demands increased. Industrial restructuring and transfer has become China's regional development strategy choice. In order to coor- 
dinate the differences in the level of development among regions, the state and local governments at all levels have introduced incentives for the transfer of industries. Due to the different stages of development in different regions, more developed eastern region is facing greater environmental pollution pressure. The western region is still in the early stages of industrialization, and the industrial economy is still in the take-off stage, so it needs a lot to undertake foreign investment and the transfer of labor-intensive industries to undertake coastal areas to increase industrial production. Improving the economic strength in the process is bound to accompany a considerable number of pollution-intensive industries transfer.

With the industrial regional transfer, especially the global pollution-intensive industries from developed countries and regions to developing countries and regions of the overall trend of change, making the environmental pollution problems show a global trend. After exploring the relationship and path of industrial development and environmental protection, how to correctly handle the relationship between pollution-intensive industry transfer and environmental protection relationship is becoming one of the hot issues of regional sustainable development research. The purpose of this paper is to explore the transfer path and driving factors of China's pollution-intensive industries through spatial correlation, and to provide policy suggestions for curbing pollution transfer.

\section{Literature Review}

The study of pollution-intensive industries began in 1979, Walter put forward the "pollution haven hypothesis (PHH)" [1], and it is used to explain the phenomenon which is because of the differences in environmental standards, pollution intensive industries from developed countries transfer to the development of relatively backward countries and they ultimately cause the developing countries to become a gathering place for pollution-intensive industries. Subsequently, the verification of the $\mathrm{PHH}$ hypothesis is gradually emerging, mainly from environmental regulation, foreign direct investment, foreign trade and other aspects, which aims to establish relevant relationship between variable model for empirical research. Siebert [2] introduces environmental factors into the $\mathrm{H}-\mathrm{O}$ model, making the scarcity of the environment as one of the production factors that affect a country's comparative advantage, so that the transfer of polluting industries can be achieved through international trade. Jaffe et al. [3], inspired by industry life cycle theory, argue that the development phase is the main reason for the transition to developed countries from developing countries to pollution industries. Baumol and Oates [4] systematically proved the "pollution sanctuary hypothesis" and pointed out that the lower threshold of environmental access is the reason why developing countries have gradually become the pollution gathering place for the transfer of polluting industries in developed countries. Long and Siebert (1991) argue that in the perfectly competitive market, the government levies a sewage tax to reduce the rate of return on capital, which in turn drives capital flows abroad and transfers pollution-intensive in- 
dustries. Mani and Wheeler [5] also argue that harsh environmental standards in rich countries have forced pollution industries to shift to developing countries that are more liberal in environmental regulation.

Liu Qiaoling, Wang Qi et al. [6] studied the distribution and trend of pollution-intensive industries in China, and found that the power industry, agricultural food processing industry since 2001 has shown a trend from the east to the central and western regions, paper products industry, Non-metallic mineral products industry since 2006 to the central and western transfer, and chemical raw materials and chemical manufacturing industry, ferrous metal smelting and rolling processing industry has not yet shown a significant shift to the central and western trends. He Longbin (2013) [7] learned through the research on the panel data of industrial products related to pollution-intensive industries in China, it is revealed that the western region is becoming the net transfer area of the pollution-intensive industry, and the northeastern region becomes the net transfer area of the pollution-intensive industry. Zhang Jingjin et al. (2015) [8]. Zhang Jingjin, et al. (2015) [8] analyzed the trend of pollution-intensive industries in China from two perspectives: regional and industrial perspectives through deviation-share analysis. The research on the causes of pollution industry is mainly focused on factor endowment and environmental regulation.

Overview of the relevant research results, the existing literature usually looks the region as an independent space in the empirical analysis of the choice of methods preferred in the traditional measurement methods, ignoring the openness of economic system and the characteristics of industrial agglomeration between multi-regional spaces. The spatial spillover effect caused by spatial agglomeration and the spatial correlation of each variable are difficult to solve by the traditional method. Adding spatial factors into model analysis will make the research more scientific and rigorous. Therefore, this paper uses space panel data to analyze the time and space of pollution-intensive industrial agglomeration in China, and based on Weber's industrial location theory combined with the features of pollution intensive industries on the transfer of driving factors were studied.

\section{The Selection of Pollution Intensive Industries}

In the definition of pollution-intensive industries, different scholars define different methods, pollution-intensive industries refers to the production process in the production of a large number of hazardous substances industry, harmful substances, including air pollutants such as sulfur dioxide, dust, water pollutants, and solid Waste. Based on the data availability and the analysis of this paper, we use the classification method of Liu Qiaoling et al. [6] to construct the pollution-intensive index based on pollution intensity and emission scale to determine the representative industry of pollution-intensive industries. The process is as follows:

$i$ Industry's Pollution intensity $E_{i}=i$ industry's emission amount $/ i$ industry's Industrial added value

$i$ Industry's Pollutant discharge scale $P_{i}=i$ industry's emission amount/All 
industrial sectors Pollutant emissions

$$
\bar{E}_{i}=\frac{E_{i}-\min \left(E_{i}\right)}{\max \left(E_{i}\right)-\min \left(E_{i}\right)}, \quad \bar{P}_{i}=\frac{P_{i}-\min \left(P_{i}\right)}{\max \left(P_{i}\right)-\min \left(P_{i}\right)}
$$

Build pollution-intensive index $A_{i}=\left(\bar{E}_{i} \times\left(\bar{P}_{i}\right)\right)^{\frac{1}{2}}$ and then the industry's waste gas, waste water, solid waste pollution-intensive index of equal weight and average derived from the industry's comprehensive pollution-intensive index.

Selection of each pollutant emissions and industrial output in 2007 as a benchmark, the data from China's environment statistical yearbook and China's industrial statistics yearbook, synthetic pollution intensive index, the greater the means an industry of some pollutants are more serious. Through calculation, the selection of electric power, heat production and supply industry (0.340), paper industry (0.296), ferrous metal mining industry (0.284), non-metallic mineral products industry (0.229), nonferrous metal mining industry (0.177), chemical raw materials and chemical products manufacturing industry (0.144), ferrous metal smelting and rolling processing industry $(0.124)$, petroleum processing, coking and nuclear fuel processing industry (0.106), the textile industry $(0.092)$ and other pollution-intensive index of the top ten industries for the pollutionintensive representative industry.

\section{Model Setting}

\subsection{Spatial Autocorrelation}

The spatial autocorrelation between variables can be used to examine whether the variables interact geographically and have potential spatial dependencies. The most commonly used method is the Moran's $I$ test. The formula is:

Global Moran' $I=\frac{\sum_{i=1}^{n} \sum_{j=1}^{n} W_{i j}\left(Y_{i}-\bar{Y}\right)\left(Y_{j}-\bar{Y}\right)}{S^{2} \sum_{i=1}^{n} \sum_{j=1}^{n} W_{i j}}$

Local Moran's $I=\frac{\left(Y_{i}-\bar{Y}\right)}{S^{2}} \sum_{j=1}^{n} W_{i j}\left(Y_{j}-\bar{Y}\right)$

$S^{2}=\frac{1}{n} \sum_{i=1}^{n}\left(Y_{i}-\bar{Y}\right)^{2}, Y_{i}$ represents $i$ area's industrial output value of pollutionintensive industries, $n$ represents the total number of districts, $W_{i}$ represents binary adjacency spatial weight matrix. When area $i$ and area $j$ adjacent, $W_{i j}=1$,on the contrary, $W_{i j}=0$.

The global Moran's I examines the spatial agglomeration of the entire spatial sequence in the range of $(-1,1)$. If it is positive and indicates that the development level of the pollution-intensive industries in each region is positively correlated, the significance test shows that the development level of pollutionintensive industries in each region is negatively correlated with space, and if it is close to zero, there is no spatial correlation. Local inspection of a region is near the space gathering situation. In this paper, the global Moran's I index shows whether the regional industrial output value of pollution-intensive industries is 
spatial dependency, and the change of local Moran's I scatter plot reflects the spatial correlation and transfer path of pollution-intensive industries in China.

\subsection{Space Panel Model}

An attribute value on a spatial unit is often affected by the value of the attribute of the neighboring spatial element, ie, that the space is interrelated. Anselin [9] incorporated spatial factors into the classical econometric model, to a certain extent make up the errors caused by the classical metrological model neglecting the direct spatial correlation of variables. The spatial measurement model mainly includes three types: spatial lag model (SAR), spatial error model (SEM) and space Durbin model (SDM).

Spatial lag model (SAR): This model mainly investigates whether a variable has significant spillover or diffusion in a certain region. The basic expression is:

$$
y_{i t}=\rho W y_{i t}+X_{i t} \alpha+\mu_{i}+\lambda_{i}+\varepsilon_{i t} \quad \varepsilon_{i t} \sim N\left(0, \sigma^{2} I\right)
$$

$y$ represents dependent variable, $X$ represents independent variable. $i$ represents section dimension, $t$ represents time dimension, $\mu_{i}$ represents individual fixed effect, $\lambda_{i}$ represents time fixed effect, $W$ represents spatial weight matrix, $\rho$ represents spatial regression coefficient, Reflect the direction and extent of the observed value of the adjacent area to the observed value of the area. $\varepsilon_{i t}$ represents the random error term, subject to normal distribution.

Spatial error model (SEM): The model mainly investigates the spatial dependence of adjacent regions and regions in error perturbations. The expression is:

$$
\begin{aligned}
& y_{i t}=X_{i t} \alpha+\mu_{i}+\lambda_{i}+\varphi_{i t} \\
& \varphi_{i t}=\beta W \varphi_{i t}+\varepsilon_{i t}
\end{aligned}
$$

$\varphi_{i t}$ represents space error term, $\beta$ represents spatial error autocorrelation coefficient, reflecting the direction and extent of the influence of the observations of the adjacent areas on the observations of the region.

Spatial Durbin model (SDM): The model considers the spatial correlation of the dependent variable and the spatial autocorrelation of the residual term. It can also analyze the influence of the dependent variable on the independent variables in the region and the influence of the independent variables and the dependent variables. Spatial lag model, spatial error model is a special form of space Durbin model. The expression is:

$$
y_{i t}=\rho W y_{i t}+X_{i t} \beta+\gamma W X_{j t}+\mu_{i}+\lambda_{i}+\varepsilon_{i t}
$$

$H_{0}: \gamma=0$ test can verify that the space Durbin model can be simplified as a spatial hysteresis model; $H_{0}: \gamma+\rho \beta=0$ test can verify that Spatial Durbin model can be simplified as a spatial error model.

\section{Variable Selection and Data Sources}

\subsection{Variable Selection}

1) Dependent variable. In order to further explore the driving factors of the 
transfer of pollution-intensive industries in China, the related research suggests that the transfer of certain industries in the region will inevitably bring about the decrease of real estate output and the increase of real estate value. This paper draws lessons from the experience of existing literature, the industrial output value of pollution-intensive industries accounts for the proportion of $Y$ as the explanatory variables to measure the degree of transfer of pollution-intensive industries [10].

2) Independent variable. In this paper, the transport infrastructure (Trans), labor cost (Awage), pollution-intensive industrial agglomeration index (LQ) into the analytical framework. In addition, the factors that affect the transfer of pollution-intensive industries are environmental regulation, capital, technology, etc., so the environmental regulation (ER), capital (K), technology (Tech), into the model. The specific model variables are described in the following Table 1:

a) Industrial agglomeration can reduce the cost by sharing the resources of the region, such as infrastructure, so that the production efficiency of the enterprise can be improved. Therefore, when a strong industrial agglomeration is formed in one area, it will attract enterprises from other regions to the area. The location entropy can effectively measure the spatial distribution of a region's industry, which is the stock index of the current industry distribution. Therefore, this paper selects the location entropy index to measure the concentration of pollution-intensive industries, the specific formula is:

$$
L Q_{i j}(t)=\frac{e_{i j}(t) / \sum_{j=1}^{n} e_{i j}(t)}{\sum_{i=1}^{m} e_{i j}(t) / \sum_{i=1}^{m} \sum_{j=1}^{n} e_{i j}(t)}
$$

$e_{i j}(t)$ represents $t$ period $j$ area $i$ industry's number of employees, $i=1,2$, $3, \cdots, m$ represents there are $m$ industries in the area; $j=1,2,3, \cdots, n$ represents The whole area is divided into $n$ sub-regions. $\sum_{j=1}^{n} e_{i j}(t)$ represents $t$ period of the region $i$ industry all the number of employment, $\sum_{i=1}^{m} e_{i j}(t)$ represents $t$ period $j$ area all number of employees, $\sum_{i=1}^{m} \sum_{j=1}^{n} e_{i j}(t)$ represents $t$ period all

Table 1. Model variable description.

\begin{tabular}{|c|c|c|}
\hline & Name & Definitions \\
\hline $\mathrm{y}$ & Industrial Transfer & $\begin{array}{l}\text { The proportion of the industrial sales value of the } \\
\text { pollution-intensive industries in the various regions } \\
\text { of the country. }\end{array}$ \\
\hline LQ & Agglomeration index & $\begin{array}{l}\text { Taking the location entropy of the employment of } \\
\text { pollution-intensive industries. }\end{array}$ \\
\hline ER & Environmental regulation & $\begin{array}{l}\text { The construction project "three simultaneous" } \\
\text { environmental investment, sewage charges income, } \\
\text { pollution control facilities operating costs and said. }\end{array}$ \\
\hline Trans & The transport infrastructure & Traffic density \\
\hline $\mathrm{K}$ & Capital & Total investment in fixed assets \\
\hline Tech & Technology & The number of three patent applications accepted \\
\hline Awage & Labor cost & The average wage of workers in the post \\
\hline
\end{tabular}


number of employees, When $L Q_{i j}(t)<1$, Said distribution industry $I$ in period $t j$, relatively scattered; when $L Q_{i j}(t)>1$, Said distribution industry $I$ in period $t$ $j$, relatively scattered.

b) The measure of the intensity of environmental regulation, different measures of scholars, one is direct evaluation index such as Liu Chao (2014) [11] using GDP/Energy measurement, Xiao Xingzhi (2013) [12] pollution control investment as a share of GDP is used to measure, another kind is the indirect evaluation indexes such as Lu Yang (2009) [13], the per capita income level as proxy variable of the intensity of environmental regulation,

This paper from the perspective of the cost of pollution control to measure the cost of environmental regulation, the construction project "three simultaneous" environmental investment reflects the cost of pollution prevention and control enterprises to pay; pollution control facilities operating costs on behalf of enterprises to maintain pollution control facilities to pay the cost, the sewage charges is an important market-based environmental regulation tool to encourage the use of pollution control facilities, environmental pollution control facilities are relatively high operating costs; sewage charges is the direct discharge of pollutants to the environment to pay the cost, Through the market signal to influence the behavior and decision-making of polluters in order to achieve pollution control objectives, the sum of the three companies reflect the total cost of pollution control to pay. Environmental regulation intensity, corporate pollution control costs will be a corresponding increase.

In addition, according to the "Pollution Haven Hypothesis $\mathrm{PHH}^{\text {", in other }}$ conditions are the same circumstances, different countries and regions, environmental regulations are different, because the lower environmental regulation intensity of countries and regions, lower environmental costs, thus attracting pollution Intensive business to its transfer, neoclassical economics also believes that strict environmental protection policies will increase the manufacturers of private costs, thereby hindering the growth of manufacturers productivity and reduce the market competitiveness of products, therefore, environmental regulation is the impact of pollution-intensive An important factor in the transfer of enterprises. But different from the "pollution paradise hypothesis", Porter (1991) [13] proposed that strict environmental protection policies can be forced against pollution-intensive industries for technological innovation, reduce production costs, improve production efficiency and make products more competitive. It can be seen that the intensity of environmental regulation on the development of pollution-intensive industries on the one hand it inhibit the development of pollution intensive industries, on the other hand it can also promote its technological innovation. Therefore, in addition to taking into account the variables of environmental regulation intensity variables; this paper introduces its secondary term to explore the impact of environmental regulation intensity on pollution-intensive industries.

\subsection{Data Sources}

Due to the availability of data, the measurement of this paper is based on the da- 
ta of 30 provinces, municipalities and autonomous regions (excluding Tibet) from 2002 to 2014. The original data are from China's Statistical Yearbook, China Environmental Yearbook, China Industrial Economics Statistical Yearbook and Regional Statistical Yearbook. In order to improve the credibility and accuracy of the estimation and reduce the influence of the analysis error on the possible price fluctuation, this paper uses the household consumption price index to convert all data to the same price in 1990, in order to obtain a more stable timing Data, this article on the use of natural variables to take some of the variables.

\section{Empirical Analysis}

\subsection{Spatial Correlation Analysis of Pollution-Intensive Industry}

The use of China's 30 provinces and autonomous regions (excluding Tibet) 2002-2014 pollution-intensive industries industrial output value (1990 constant price) accounted for the proportion of the national pollution-intensive industries industrial output value, calculate the overall and plot out the scatter, The results shown in Table 2 and Figure 1, data processing and calculation using Geoda 1.6.7 software to complete.

Table 2 data show that the regional output of pollution-intensive industries accounted for the proportion of the national total in the $1 \%$ of the significance level are positive, that is, there is a high degree of spatial positive correlation, and the global index in 2002-Remained at around 0.30 in 2014, and the spatial positive correlation continued to be stable. The first quadrant ( $\mathrm{HH}$ aggregation) indicates that the region with high output value is surrounded by other areas of high output value; the second quadrant ( $\mathrm{LH}$ pool) represents the low output

Table 2. 2002-2014 global Moran's I index of industrial output value of pollution-intensive industry in 31 provinces of China.

\begin{tabular}{cccccc}
\hline Year & Moran's $I$ & $E(I)$ & $s d(I)$ & $Z$ & $P$-value \\
\hline 2002 & 0.3020 & -0.0345 & 0.1125 & 3.0100 & 0.005 \\
2003 & 0.3264 & -0.0345 & 0.1109 & 3.2302 & 0.005 \\
2004 & 0.3308 & -0.0345 & 0.1182 & 3.1007 & 0.007 \\
2005 & 0.3455 & -0.0345 & 0.1121 & 3.3568 & 0.005 \\
2006 & 0.2950 & -0.0345 & 0.1103 & 3.0110 & 0.005 \\
2007 & 0.3471 & -0.0345 & 0.1144 & 3.3090 & 0.003 \\
2008 & 0.2965 & -0.0345 & 0.1087 & 3.0490 & 0.007 \\
2009 & 0.3257 & -0.0345 & 0.1121 & 3.2084 & 0.005 \\
2010 & 0.3257 & -0.0345 & 0.1195 & 2.9932 & 0.005 \\
2011 & 0.3269 & -0.0345 & 0.1139 & 3.1601 & 0.006 \\
2012 & 0.3282 & -0.0345 & 0.1073 & 3.3717 & 0.006 \\
2013 & 0.3058 & -0.0345 & 0.1100 & 3.0890 & 0.007 \\
\hline
\end{tabular}



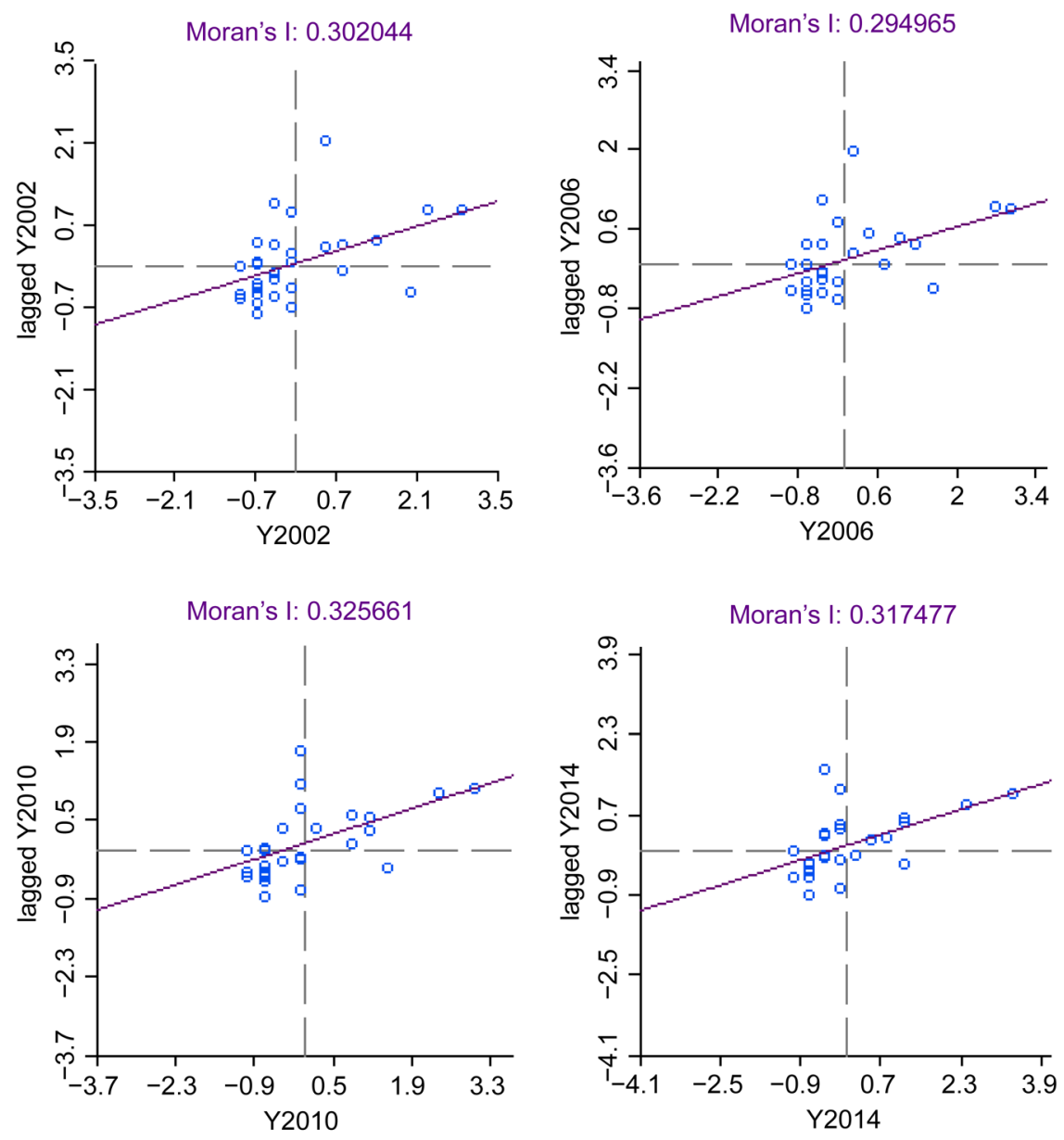

Figure 1. 2002, 2006, 2010, 2014 China's provinces pollution-intensive industries' industrial output value of the national share of the scatter.

value The area is surrounded by high-yielding areas; the third quadrant (LL agglomeration) is the area where the low-yielding area is surrounded by other areas of low value; the fourth quadrant (HL cluster) represents the high value of the region Surrounded by. Wherein the first quadrant and the third quadrant represent positive spatial autocorrelation, and the second quadrant and the fourth quadrant represent negative spatial autocorrelation. Most of the provinces in 2002-2014 shown in Figure 1 are located in the typical quadrant and the third quadrant of the typical observation area.

Further observation of the scatter plot can be found in the province of pollution-intensive industries of space dynamic transition process, that is, 2002-2014 thirteen years of China's pollution-intensive industries transfer path.

The spatial distribution pattern of pollution-intensive industries in China has changed from 2002 to 2014, among which Jilin, Liaoning, Hubei, Shanghai, Guangxi and pollution-intensive industries have undergone significant transitions during the inspection period, and the remaining provinces have occurred in quadrant 1) Yangtze River Delta region such as Shanghai, Jiangsu, Zhejiang in 2002 in the $\mathrm{HH}$ quadrant that is pollution-intensive industries high gathering area, but thirteen years from Shanghai to $\mathrm{HH}$ transition to the $\mathrm{LH}$, the location of the 
change, Jiangsu and Zhejiang have to LH transition trend shows that pollution-intensive industries in the Yangtze River Delta region occurred in the industry out of the degree of agglomeration weakened. 2) the southeastern coastal areas, Guangdong Province in 2002 in the HL pollution-intensive industries in the high gathering area, thirteen years to the LL transition trend, indicating the existence of industry out, Fujian, Hainan 2002 pollution-intensive industries in the gathering area, In recent years, the trend of low agglomeration is more obvious, indicating that the industry out. 3) In the central region, Shandong, Henan and Hebei were in the high agglomeration area in 2002, the trend of $\mathrm{HH}$ was more obvious in 2014, and the trend from the $\mathrm{LH}$ quadrant to the $\mathrm{HH}$ transition indicated that the concentration of pollution-intensive industries was higher. Anhui and Hunan in 2002-2014 to HH transition trend is obvious, Hubei from LL transition to HL, indicating the existence of industry transfer 4) Northeast, Liaoning from $\mathrm{HL}$ to $\mathrm{HH}$ transition to indicate that the concentration of pollution-intensive industries than the surrounding areas More obvious, Jilin and Heilongjiang agglomeration degree is down. 5) The trend of transfer to HL in Sichuan, Chongqing, Guizhou, Shanxi, Ningxia, Gansu, Inner Mongolia, Yunnan, Qinghai and Xinjiang has increased, and the concentration of pollution- intensive industries has increased.

\subsection{Spatial Panel Model Analysis}

\section{Model Selection}

In this paper, we use Elhorst (2012) [14] method to select three spatial panel models, such as spatial lag model, spatial error model and spatial Durbin model. Firstly, the LM test is carried out on the non-spatial panel model, that is, without considering any spatial correlation or robust LM test (Robust LM test), if the non-spatial panel model is rejected, indicating that there is spatial correlation between variables or residuals, the space panel model should be used, otherwise the common panel model should be used. If the model shows that there is spatial correlation, the next step is on the two assumptions of the space Durbin model $H_{0}: \gamma=0$ and $H_{0}: \gamma+\rho \beta=0$, and the Wald test and the LR test. If the first hypothesis test is used to indicate that the model can be simplified as a SAR model; if the first hypothesis test is used, it indicates that the model can be simplified as an SEM model; if two assumptions are significantly rejected, the SDM model should be selected.

Using the MATLAB 2010a and Elhorst toolboxes, the LM test and the Robust LM test were performed on the non-spatial panel model. The results are shown in the Table 3:

As can be seen from the results shown in the table above, the generic panel model LM test and the Robust LM test reject the "model does not contain the spatial hysteresis" and the "model does not contain autocorrelation residuals" at the $1 \%$ significance level In the space-constrained panel model, the two tests also reject the hypothesis that the model does not contain the spatial hysteresis and the model does not contain the autocorrelation residual term at the $1 \%$ significance 
Table 3. No space panel effect LM test and Robust LM test.

\begin{tabular}{|c|c|c|c|c|}
\hline & $\begin{array}{l}\text { Ordinary } \\
\text { OLS }\end{array}$ & $\begin{array}{c}\text { Space-fixed } \\
\text { OLS }\end{array}$ & $\begin{array}{c}\text { Time-fixed } \\
\text { OLS }\end{array}$ & $\begin{array}{c}\text { Space and } \\
\text { time-fixed OLS }\end{array}$ \\
\hline$L Q$ & $\begin{array}{c}0.0172^{* * *} \\
(9.4300)\end{array}$ & $\begin{array}{c}0.0177^{* * *} \\
(9.9779)\end{array}$ & $\begin{array}{c}0.0197^{* * *} \\
(8.5239)\end{array}$ & $\begin{array}{c}0.0208^{\star * *} \\
(9.0237)\end{array}$ \\
\hline LnER & $\begin{array}{c}-0.4151^{* * *} \\
(-8.0424)\end{array}$ & $\begin{array}{c}-0.4534^{* * *} \\
(-8.9044)\end{array}$ & $\begin{array}{c}-0.3324^{\star * *} \\
(-6.6451)\end{array}$ & $\begin{array}{c}-0.3552^{\star * *} \\
(-7.2341)\end{array}$ \\
\hline$(L n E R)^{2}$ & $\begin{array}{c}0.0237^{* * *} \\
(8.4558)\end{array}$ & $\begin{array}{c}0.0258^{* * *} \\
(9.3358)\end{array}$ & $\begin{array}{c}0.0193^{* * *} \\
(6.9968)\end{array}$ & $\begin{array}{c}0.0205^{\star * *} \\
(7.5985)\end{array}$ \\
\hline Trans & $\begin{array}{l}0.0099^{* * *} \\
(3.6420)\end{array}$ & $\begin{array}{l}0.0105^{* * *} \\
(4.0135)\end{array}$ & $\begin{array}{l}0.0063^{* *} \\
(2.1443)\end{array}$ & $\begin{array}{l}0.0071^{* *} \\
(2.5366)\end{array}$ \\
\hline $\operatorname{LnK}$ & $\begin{array}{l}0.0165^{\star * *} \\
(2.7467)\end{array}$ & $\begin{array}{l}0.0135^{\star *} \\
(2.2908)\end{array}$ & $\begin{array}{l}0.0179^{* * *} \\
(2.8068)\end{array}$ & $\begin{array}{l}0.0139^{* *} \\
(2.2592)\end{array}$ \\
\hline LnTech & $\begin{array}{l}0.0141^{* * *} \\
(4.4565)\end{array}$ & $\begin{array}{c}0.0157^{* * *} \\
(5.0506)\end{array}$ & $\begin{array}{c}0.0103^{\star * *} \\
(2.9792)\end{array}$ & $\begin{array}{c}0.0125^{\star * *} \\
(3.6668)\end{array}$ \\
\hline LnAwage & $\begin{array}{l}-0.0844^{* * *} \\
(-13.3426)\end{array}$ & $\begin{array}{l}-0.0844^{* * *} \\
(-13.9992)\end{array}$ & $\begin{array}{c}-0.0751^{\star * *} \\
(-8.8895)\end{array}$ & $\begin{array}{c}-0.0741^{\star * *} \\
(-9.1411)\end{array}$ \\
\hline$C$ & $\begin{array}{c}1.9114^{* * *} \\
(7.9771)\end{array}$ & & & \\
\hline$R^{2}$ & 0.7179 & 0.7346 & 0.5778 & 0.5928 \\
\hline$\sigma^{2}$ & 0.0003 & 0.0003 & 0.0002 & 0.00002 \\
\hline LM test no spatial lag & $\begin{array}{l}186.1182 \\
\mathrm{P}=0.000\end{array}$ & $\begin{array}{l}179.5259 \\
P=0.000\end{array}$ & $\begin{array}{l}115.7132 \\
\mathrm{P}=0.000\end{array}$ & $\begin{array}{l}105.1993 \\
P=0.000\end{array}$ \\
\hline robust LM test no spatial lag & $\begin{array}{c}7.7525 \\
\mathrm{P}=0.005\end{array}$ & $\begin{array}{c}7.8609 \\
P=0.005\end{array}$ & $\begin{array}{c}2.4850 \\
\mathrm{P}=0.115\end{array}$ & $\begin{array}{c}2.4518 \\
\mathrm{P}=0.117\end{array}$ \\
\hline LM test no spatial error & $\begin{array}{l}250.7538 \\
P=0.000\end{array}$ & $\begin{array}{l}246.0372 \\
P=0.000\end{array}$ & $\begin{array}{l}158.6566 \\
P=0.000\end{array}$ & $\begin{array}{l}147.1975 \\
P=0.000\end{array}$ \\
\hline robust LM test no spatial error & $\begin{array}{c}72.3881 \\
\mathrm{P}=0.000\end{array}$ & $\begin{array}{c}74.3722 \\
\mathrm{P}=0.000\end{array}$ & $\begin{array}{c}45.4284 \\
\mathrm{P}=0.000\end{array}$ & $\begin{array}{c}44.4560 \\
P=0.000\end{array}$ \\
\hline
\end{tabular}

Note: within the brackets for the $t$ value, ${ }^{*},{ }^{* *},{ }^{* *}$, respectively, said $10 \%, 5 \%, 1 \%$ of the significance level.

level; In the panel model, the LM test rejects the above two assumptions at the $1 \%$ significance level. The Robust LM test only significantly rejects the assumption that the model does not contain the autocorrelation residual term. In the time-space dual fixation model, LM The test rejects the two hypotheses at the $1 \%$ significance level, and the Robust LM test only rejects the hypothesis that the model does not contain autocorrelation residuals. In general, the model should include the autocorrelation residual term, and whether the inclusion of the spatial hysteresis item cannot be determined.

The LR inspection aims to test whether the model has a space effect or time effect. When the $P$ value is less than 0.05 , the assumption that the space is fixed or the time is fixed. Test results, the space fixed LR is 47.9235 ( $\mathrm{P}=0.0202)$, the time fixed LR is $123.2684(\mathrm{P}=0.0000)$. Spatial fixed $\mathrm{LR}$ test and time fixed LR test showed that the model should also consider the spatial fixation and time fixation effects. 
The next step of Wald test, that is, the spatial lag model, the spatial error model, the space Durbin model to choose. For the selection of two hypotheses, when $\mathrm{P}=>0.05$, it means that the hypothesis cannot be rejected, that is, the model can be simplified, otherwise the space Durbin model is used. From the test results shown in Table 4, it can be seen that the $\mathrm{P}$ value is less than 0.05 for two assumptions that can be simplified as the spatial lag model and the spatial error model, indicating that the model cannot be simplified and the space Doberman model should be used.

\subsection{Result Analysis}

The Table 5 gives the results of the spatial fixation effect Durbin model, the time fixed effect Durbin model, and the space time double fixation effect.

The LM test results show that the model should be chosen to estimate the space Durbin model. According to the results of the LR test, the model should also consider the spatial effect and the time effect. The traditional model $R^{2}$ is based on the residual sum of the residuals and is no longer applicable to the judgment of the spatial effect model. Elorst considers Corrected $R^{2}$ to be more reasonable for the panel data model with the spatial lag dependent variable. From the above table we can see that the space-fixed Doberman model has the best degree of fitting. In addition, the spatial effect reflects the effect of the variable with space on the dependent variable. The time effect reflects the effect of the variable with time on the dependent variable. In this paper, the time span is short and the effect of time fixed effect is small. The research focus is on regional differences. Therefore, the Durbin model of space fixed effect is chosen to study the driving factors of pollution-intensive industry transfer.

In order to correctly explain the influence of the independent variable on the dependent variable, Lesage and Pace [15] propose the direct effect, the indirect effect and the total effect, and the direct effect of the independent variable, the direct effect, the direct effect, the direct effect The effect represents the average effect of the independent variable on the dependent variable in the region. The indirect effect represents the average effect of the independent variable on the dependent variable in the neighboring region. The total effect represents the average effect of the independent variable on all dependent variables (Table 6).

1) The coefficient of direct effect of LQ pollution-intensive industry is 0.0188 , and the hypothesis test on $1 \%$ significance level shows that the concentration of

Table 4. Wald test of space panel model.

\begin{tabular}{cccc}
\hline & Space-fixed OLS & Time-fixed OLS & Space and time-fixed OLS \\
\hline Wald_spatial_lag & 149.4609 & 94.4517 & 103.9954 \\
P-value & 0.0000 & 0.0000 & 0.0000 \\
Wald_spatial_error & 24.6190 & 27.8356 & 24.1635 \\
P-value & 0.0000 & 0.0000 & 0.0011 \\
\hline
\end{tabular}


Table 5. Four effects setting results of space Durbin model.

\begin{tabular}{|c|c|c|c|c|}
\hline & $\begin{array}{l}\text { Ordinary } \\
\text { OLS }\end{array}$ & $\begin{array}{l}\text { Space-fixed } \\
\text { OLS }\end{array}$ & $\begin{array}{l}\text { Time-fixed } \\
\text { OLS }\end{array}$ & $\begin{array}{c}\text { Space and time-fixed } \\
\text { OLS }\end{array}$ \\
\hline intercept & $\begin{array}{c}1.1088^{* * *} \\
(4.5219)\end{array}$ & & & \\
\hline$L Q$ & $\begin{array}{c}0.0178^{* * *} \\
(8.1598)\end{array}$ & $\begin{array}{c}0.0192^{* * *} \\
(8.3958)\end{array}$ & $\begin{array}{c}0.0187^{\star * *} \\
(8.1253)\end{array}$ & $\begin{array}{c}0.0175^{\star * *} \\
(7.8250)\end{array}$ \\
\hline LnER & $\begin{array}{c}-0.1941^{* * *} \\
(-4.7339)\end{array}$ & $\begin{array}{c}-0.2114^{* * *} \\
(-4.9967)\end{array}$ & $\begin{array}{c}-0.2218^{\star * *} \\
(-5.1729)\end{array}$ & $\begin{array}{c}-0.2064^{* * *} \\
(-4.9039)\end{array}$ \\
\hline$(L n E R)^{2}$ & $\begin{array}{c}0.0111^{\star \star \star} \\
(4.9150)\end{array}$ & $\begin{array}{c}0.0120^{* * *} \\
(5,1709)\end{array}$ & $\begin{array}{c}0.1265^{\star \star *} \\
(5.3682)\end{array}$ & $\begin{array}{c}0.0118^{* * *} \\
(5.1054)\end{array}$ \\
\hline Trans & $\begin{array}{c}0.0016 \\
(0.5388)\end{array}$ & $\begin{array}{c}0.0022 \\
(0.7062)\end{array}$ & $\begin{array}{c}0.0024 \\
(0.7883)\end{array}$ & $\begin{array}{c}0.0014 \\
(0.4601)\end{array}$ \\
\hline $\operatorname{LnK}$ & $\begin{array}{c}0.0303^{* * *} \\
(5.7121)\end{array}$ & $\begin{array}{c}0.0273^{\star * *} \\
(5.0581)\end{array}$ & $\begin{array}{c}0.0267^{\star * \star} \\
(4.8780)\end{array}$ & $\begin{array}{c}0.0293^{\star * *} \\
(5.3361)\end{array}$ \\
\hline LnTech & $\begin{array}{c}0.0141^{\star * *} \\
(4.4358)\end{array}$ & $\begin{array}{c}0.0165^{\star * *} \\
(4.9818)\end{array}$ & $\begin{array}{c}0.0162^{* * *} \\
(4.8192)\end{array}$ & $\begin{array}{c}0.0138^{\star * *} \\
(4.2360)\end{array}$ \\
\hline LnAwage & $\begin{array}{c}-0.0826^{* * *} \\
(-8.7605)\end{array}$ & $\begin{array}{c}-0.0825^{\star * *} \\
(-8.5317)\end{array}$ & $\begin{array}{c}-0.0840^{* * *} \\
(-8.6443)\end{array}$ & $\begin{array}{c}-0.0830^{* * *} \\
(-8.5570)\end{array}$ \\
\hline$W^{*} L Q$ & $\begin{array}{c}-0.0136^{* * *} \\
(-5.3467)\end{array}$ & $\begin{array}{c}-0.0149^{* * *} \\
(-5.6606)\end{array}$ & $\begin{array}{c}-0.0142^{* * *} \\
(-4.1115)\end{array}$ & $\begin{array}{c}-0.0121^{* * *} \\
(-3.5577)\end{array}$ \\
\hline$W^{*} \operatorname{LnER}$ & $\begin{array}{c}-0.0393 \\
(-5.3467)\end{array}$ & $\begin{array}{c}-0.0341 \\
(-0.5284)\end{array}$ & $\begin{array}{c}-0.0493 \\
(-6.6751)\end{array}$ & $\begin{array}{c}-0.0828 \\
(-1.1663)\end{array}$ \\
\hline$W^{*}(\operatorname{LnER})^{2}$ & $\begin{array}{c}0.0020 \\
(0.5963)\end{array}$ & $\begin{array}{c}0.0018 \\
(0.5071)\end{array}$ & $\begin{array}{c}0.0031 \\
(0.7625)\end{array}$ & $\begin{array}{c}0.0049 \\
(1.2574)\end{array}$ \\
\hline$W^{*}$ Trans & $\begin{array}{c}0.0036 \\
(0.9934)\end{array}$ & $\begin{array}{c}0.0031 \\
(0.8452)\end{array}$ & $\begin{array}{c}0.0025 \\
(0.6066)\end{array}$ & $\begin{array}{c}0.0043 \\
(1.0162)\end{array}$ \\
\hline$W^{\star} \operatorname{Ln} K$ & $\begin{array}{c}-0.0302^{\star * *} \\
(-4.5964)\end{array}$ & $\begin{array}{c}-0.0286^{* * *} \\
(-4.3047)\end{array}$ & $\begin{array}{c}-0.0339^{* * *} \\
(-3.9032)\end{array}$ & $\begin{array}{c}-0.0331^{\star * *} \\
(-3.7874)\end{array}$ \\
\hline$W^{*}$ LnTech & $\begin{array}{c}-0.0107^{\star * *} \\
(-2.7176)\end{array}$ & $\begin{array}{c}-0.0125^{\star * *} \\
(-3.1022)\end{array}$ & $\begin{array}{c}-0.0137^{\star * *} \\
(-2.8166)\end{array}$ & $\begin{array}{c}-0.0127^{\star * *} \\
(-2.6579)\end{array}$ \\
\hline$W^{*}$ LnAwage & $\begin{array}{c}0.0613^{* * *} \\
(5.6135)\end{array}$ & $\begin{array}{c}0.0606^{* * *} \\
(5.4384)\end{array}$ & $\begin{array}{c}0.0603^{\star * *} \\
(4.4906)\end{array}$ & $\begin{array}{c}0.0555^{\star * *} \\
(4.0919)\end{array}$ \\
\hline$W^{*}$ dep. var & $\begin{array}{l}0.7440^{* * *} \\
(22.8568)\end{array}$ & $\begin{array}{l}0.7370^{* * *} \\
(22.1022)\end{array}$ & $\begin{array}{l}0.7108^{\star * *} \\
(20.3753)\end{array}$ & $\begin{array}{l}0.6670^{* * *} \\
(17.5690)\end{array}$ \\
\hline Corrected $R^{2}$ & 0.8911 & 0.7755 & 0.6358 & 0.6274 \\
\hline $\log L$ & 1186.6058 & 1206.5695 & 1214.1924 & 1193.6964 \\
\hline$\sigma^{2}$ & 0.0001 & 0.0001 & 0.0001 & 0.0001 \\
\hline
\end{tabular}

Note: within the brackets for the $t$ value, ${ }^{*},{ }^{* *},{ }^{* *}$, respectively, said $10 \%, 5 \%, 1 \%$ of the significance level. 
Table 6. Spatial fixed Durbin model effect decomposition.

\begin{tabular}{ccccccc}
\hline & Direct effect & $\mathrm{T}$ & Indirect effect & $\mathrm{T}$ & Total effect & $\mathrm{T}$ \\
\hline LQ & 0.0188 & $8.7015^{* * *}$ & -0.0028 & -0.5277 & 0.0161 & $2.9741^{* * *}$ \\
LnER & -0.2735 & $-6.1449^{* * *}$ & -0.6673 & $-3.6617^{* * *}$ & -0.9408 & $-4.7243^{* * *}$ \\
$(\text { LnER })^{2}$ & 0.0155 & $6.3384^{* * *}$ & 0.0374 & $3.8090^{* * *}$ & 0.0528 & $4.9376^{* * *}$ \\
Trans & 0.0036 & 1.2429 & 0.0171 & $2.1020^{*}$ & 0.0207 & $2.4919^{* *}$ \\
LnK & 0.0245 & $4.3480^{* * *}$ & -0.0301 & -1.5995 & -0.0056 & -0.2630 \\
LnTech & 0.0165 & $5.2453^{* * *}$ & -0.0021 & -0.2202 & 0.0144 & 1.4094 \\
LnAwage & -0.0828 & $-9.7887^{* * *}$ & 0.0003 & 0.0134 & -0.0826 & $-4.2336^{* * *}$ \\
\hline
\end{tabular}

pollution-intensive enterprises is higher in each spatial unit, and the pollutionThe output value of industrial output increased by 0.6628 , and the indirect effect of -0.0028 did not pass the significance test. It indicated that the concentration of pollution-intensive industries in each region played a certain degree of inhibition to the transfer of pollution-intensive industries in adjacent areas. The total effect was 0.0161 and significant at the $1 \%$ level, indicating that for all the spatial units, the degree of agglomeration contributes to the transfer of polluting-intensive industries, and in general, the transfer of polluting-intensive industries tends to have a higher degree of agglomeration Of the region, in the high degree of enterprise agglomeration in the region, enterprises can share infrastructure, improve information flow to reduce transportation costs, transaction costs, information costs, enhance the competitiveness of enterprises.

2) The direct effect coefficient of agency variable on environmental regulation and environmental regulation is -0.2735 , which have passed the $1 \%$ significance test. It shows that for each space unit, the intensity of environmental regulation increases, and the output value of pollution-intensive industrial industry accounts for. The indirect effect coefficient is -0.6673 , which indicates that the increase of local environmental regulation intensity has an inhibitory effect on the output value of pollution-intensive industries in adjacent areas. The total effect coefficient of environmental regulation is -0.9408 and passed through $1 \%$ level. The results show that for all the spatial units, the intensity of environmental regulation increases the inhibitory effect on the pollution-intensive industries. To sum up, it can be concluded that pollution-intensive industries tend to shift to areas with weak environmental regulation. With the improvement of environmental regulation, enterprises will invest more funds to pay higher sewage charges, pollution control facilities operating costs, etc., these funds will squeeze the enterprise for production, technology research and development funds, production costs rise, so companies will choose to transfer to the relatively low cost of environmental management areas. However, the model introduces the quadratic term of the proxy variable of environmental regulation. The direct effect, indirect effect and total effect coefficient are positive values, and the significance test of $1 \%$ level shows that the intensity of environmental regulation and pollution-intensive enterprises Industrial output value of the proportion of the 
proportion of the country showed " $U$ " type, that is, the initial intensity of environmental regulation to improve pollution-intensive enterprises industrial output value of the country's share of decline, there are enterprises out, and then over time, environmental regulation strength gradually increased, pollution-intensive industries industrial output value of the proportion of the country gradually increased, indicating the existence of the enterprise.

With the increase in the intensity of environmental regulation $L n E R$, pollution-intensive enterprises show the phenomenon of the first turn after the transfer, the reason for this phenomenon is that the intensity of environmental regulation in the early stages of improvement, enterprises can only passively, in the sewage charges, pollution control The increase in production costs, rising production costs, which led to the decline in production, enterprises transferred to the relatively low intensity of environmental regulation in the region, the industry out, that is, the intensity of environmental regulation caused by the "squeeze effect"; with Environmental regulation strength continues to rise, some enterprises out or be eliminated, the remaining enterprises gradually from passive response to active response, that is, by improving the production technology to improve pollution control level, this approach not only reduces the pollution costs, but also led to the production Technological innovation, so that the overall production cost reduction, improve production efficiency and competitiveness. At this point, enterprises will not only reduce the output for industrial transfer, but also to expand the scale and increase production, that is, into the " $U$ " curve of the second half, this time the rise in environmental regulation led to the "innovation compensation effect" The proportion of industrial sales of pollutionintensive enterprises in the region accounted for the proportion of the country increased, showing a phenomenon.

3) For the traffic infrastructure, the coefficient of direct effect is 0.0036 , and the coefficient of indirect effect is 0.0171 through the significance test at $10 \%$ level. The coefficient of total effect is 0.0207 and passes through $5 \%$ on the significance of the test. It shows that the improvement of transportation infrastructure plays a positive role in promoting the transfer of pollution-intensive enterprises, which is conducive to the flow of production factors and reduce the transportation cost and transaction cost of enterprises. And the indirect effect of this promotion is more obvious than the direct effect, the reason may be that the improvement of the transport infrastructure led to the development of the local economy, the level of economic development will lead to the region will pay more attention to environmental construction, and forced Some of the pollution-intensive enterprises to move to more remote areas.

4) The direct effect coefficients of the surrogate variables on capital investment and technological progress, capital investment and technological progress were 0.0245 and 0.0165 , respectively, and the coefficient of indirect effect and total effect failed through a significant $1 \%$ Sex test. Indicating that capital investment and technological progress have played a positive role in the industrial output of pollution-intensive enterprises, and the direct effect of this impetus is 
greater than that of indirect effects, capital and technical factors in promoting the development of local pollution-intensive enterprises, To attract pollutionintensive enterprises in the transfer area is more obvious than the adjacent areas

5) The direct effect coefficient of labor cost and average wage is -0.0828 , and it is significant at $1 \%$ level, the indirect effect coefficient is 0.0134 , which cannot pass the significance test, the total effect coefficient is -0.0826 , Horizontal significance test. It shows that for the various units of space, the average wage increases, the industrial output value of pollution-intensive enterprises nationwide decline, the existence of enterprises out, rising labor costs on the adjacent areas played a positive role, due to rising labor costs, business to labor costs Low adjacent areas to transfer. Weber's industrial location theory, companies tend to choose capital, labor and other factors of production is more abundant, so the labor costs of pollution-intensive enterprises directly greater than the indirect effect.

\section{Conclusions and Policy Recommendations}

\subsection{Conclusions}

This paper uses the panel data of 30 regions in China from 2002 to 2014 to study the transfer path and driving factors of pollution-intensive industries in China from 2002 to 2014 . The conclusions are as follows:

1) Using the global spatial autocorrelation coefficient (Moran' $I$ ) to obtain the index scatter plot of the industrial output value of pollution-intensive enterprises in different provinces in 2002-2004, the results show that China's regional pollution-intensive industries spatial distribution has significant spatial dependence and presents positive spatial autocorrelation, that is, the spatial distribution of pollution-intensive industries in China presents a certain agglomeration phenomenon.

2) By further observing Moran' I scatter gram, we can find that the spatial distribution of pollution-intensive industries in China has been adjusted in 2002-2014. The pollution-intensive industries in the provinces have been continuously moving in and out. In general, China's pollution-intensive industries in the eastern regions such as Shanghai, Beijing, Tianjin, Jiangsu, Zhejiang, Guangdong and other regions continue to decline, and continue to turn out the enterprise, the central and western regions such as Henan, Shanxi, Hebei, Sichuan and other places intensive industrial agglomeration increased, the central and western regions undertake the pollution-intensive enterprises which from the eastern coastal areas.

3) In addition, this paper explores the driving factors of the pollution-intensive industry transfer by using the space Durbin model regression in 30 regions of China from 2002 to 2014. The results show that the degree of agglomeration, transportation infrastructure, technological progress and capital investment has a positive effect on the transfer of pollution-intensive industries. Labor costs have a negative effect on the transfer of pollution-intensive industries. Environ- 
mental regulation is responsible for pollution-intensive industries there is a two-way effect, the initial increase in environmental regulation intensity, enterprises passive response, sewage charges, pollution control facilities operating costs and other environmental costs rise, resulting in reduced production or transfer to the lower intensity of environmental regulation areas, environmental regulation "the upper hand". As the intensity of environmental regulation continues to rise, enterprises begin to improve production technology, the use of cleaner production equipment, which will also lead to the overall production efficiency of enterprises, production increased. The environmental regulatory innovation compensation effect gradually.

\subsection{Policy Recommendations}

1) With the different stages of economic development in different regions of China, pollution-intensive industrial transfer is the inevitable result of economic restructuring, but pollution-intensive industries should follow the correct transfer path, and should take into account the environmental carrying capacity. The problem of pollution transfer in the process of industrial transfer cannot reduce the threshold of transferring to the environment on the basis of promoting short-term economic growth. The impact of the transfer to the environment cannot exceed its environmental carrying capacity, and the relevant departments should be the scientific reasonably industrial planning. The establishment of a reasonable environmental standards system aims to limit the backward production capacity. Relevant departments should establish a reasonable environmental standards system, strengthen environmental law enforcement efforts.

2) In the long term, the improvement of environmental regulation can lead to the improvement of production technology, the use of clean technology and the improvement of production efficiency in pollution-intensive industries. Therefore, the transfer of polluting industries does not necessarily bring about the transfer of pollutants. To achieve environmental and economic win-win situation, the key is to take effective incentive mechanism; not only to pollute enterprises to charge higher sewage charges, the implementation of more stringent penalties, but also to encourage enterprises to improve pollution control technology and cleaner production. Technology, such as the development of corporate pollution control technology to give preferential tax subsidies, etc.

3) In addition to considering the intensity of environmental regulation into the land, the pollution-intensive enterprises should also consider the industrial location factors, such as the degree of agglomeration, traffic conditions, labor costs, capital and technological progress etc., and in addition to the transfer to the low level of environmental regulation to reduce the cost of enterprises, which is not a long-term plan, polluting enterprises in order to not only obtain rapid development, but also actively carry out the upgrading of production technology innovation, the use of clean technology, research and development of pollution control technology, eliminate backward equipment, reduce the environmental cost of enterprises and improve the added value of the product. 


\section{References}

[1] Walter, I. and Ugelow, J. (1979) Environmental Policies in Developing Countries. AMBIO, 8, 102-109.

[2] Siebert, H. (1977) Environmental Quality and the Gains from Trade. Kyklos, 30, 657-673. https://doi.org/10.1111/j.1467-6435.1977.tb02694.x

[3] Jaffe, A.B., Peter, S.R., Portney, P.R., et al. (1995) Environmental Regulation and the Competitiveness of U.S. Manufacturing: What Does the Evidence Tell Us? Journal of Economic Literature, 33, 132-163.

[4] Baumol, W.J. and Oates, W. (1988) The Theory of Environmental Policy. Cambridge University Press, Cambridge. https://doi.org/10.1017/CBO9781139173513

[5] Mani, M. and Wheeler, D. (1997) In Search of Pollution Havens: Dirty Industry Migration in the World Economy. World Bank Working Paper, Washington DC, 16.

[6] Liu, Q.L., Wang, Q. and Li, P. (2012) Changes in Pollution-Intensive Industry and Its Regional Distribution in China. Ecological Economy, 1, 107-112.

[7] He, L.B. (2013) Inter-Regional Transfer Path and Indices of Domestic Pollution-Intensive Industry-Based on Panel Data for Industrial Products Related to 2000-2011. Economist, 6, 78-86.

[8] Zhang, J.J. and Wang, Y. (2015) Spatial Agglomeration and Regional Transfer of China's Pollution-Intensive Industry. Industrial Technology Economy, 8, 3-11.

[9] Anselin, L. (2001) Spatial Effects in Econometric Practice in Environmental and Resource Economics. America Journal of Agricultural Economics, 83, 705-710.

[10] Zhang, C.Y. and Qing, G.Y. (2015) Can the Pollution Industry Transfer Achieve a Win-Win Economy and Environment? Research on the Perspective of Environmental Regulation. Financial Research, 41, 96-108.

[11] Xiao, X.Z. and Li, S.L. (2013) A Study on the Dynamic Impact of Environmental Regulation on Industrial Upgrading. Economic Theory and Economic Management, 6, 102-112.

[12] Lu, Y. (2012) An Environmental Pollution Problem from an Open Macro Perspective: A Review. Economic Research, 2, 146-158.

[13] Porter, M.A. (1991) America’s Green Strategy. Scientific America, 264, 168. https://doi.org/10.1038/scientificamerican0491-168

[14] Elhorst, J.P. (2012) Mat lab Software for Spatial Panels. International Regional Science Review, 26, 244-68. https://doi.org/10.1177/0160017603253791

[15] Lesage, J.P. and Pace, R.K. (2010) Spatial Economic Model. Handbook of Applied Spatial Analysis, Springer Berlin, Heidelberg, 377-407. 